Eskişehir Osmangazi Üniversitesi Mühendislik ve Mimarlık Fakültesi Dergisi 26(3), 123-131, 2018
The Journal of Engineering and Architecture Faculty of

Eskisehir Osmangazi University 26(3), 123-131, 2018

\title{
MERMER ATIĞI İLAVESİ İLE MAT SIR BİLEŞİMLERİNİN ÜRETIMİ
}

\author{
Selvin YEŞİLAY* \\ Anadolu Üniversitesi, Güzel Sanatlar Fakültesi, Cam Bölümü, Eskişehir, Türkiye. \\ e-posta : syesilay@anadolu.edu.tr ORCID No : http://orcid.org/0000-0002-8217-3874
}

DOI : http://dx.doi.org/10.31796/ogummf.412312

Makale Geliș : 03.04 .2018

Makale Kabul : 09.10.2018

Araştırma Makalesi

\section{Mermer Atığı İlavesi ile Mat Sır Bileşimlerinin Üretimi}

Öz

Mermerin tüm dünyadaki yaygın kullanımıyla birlikte, mermer madenciliği ve üretilen atık miktarı da artmıștır. $\mathrm{Bu}$ çalıșmada, yerel bir mermer ișletmesinden alınan mermer tozları farkl oranlarda standart mat sir kompozisyonunda kullanılmış ve etkileri incelenmiștir. Mermer atıklarının sir yapısının özelliklerine olan etkileri; mikroyapıda meydana gelen değişiklikler ve faz oluşumları, ısıl davranıș, renk parametreleri ve sir yüzeylerinin parlaklığı bakımından araștırılmıștır. Hazırlanan sır reçetelerine renk üzerindeki etkilerini incelemek amacı ile bakır oksit (CuO) ilave edilmiştir. Renklendirici oksit kullanılmadan hazırlanan reçetelerde \% 20'nin üzerinde mermer atığı içeren sırlarda beyazlık değeri bir miktar artmıştır. Atık miktarı arttıkça, sır yüzeyinde metalik görüntü ve daha derin bir doku oluşmuștur. Çalışmanın son aşamasında üretilen sırlar seramik formlara uygulanmıștır.

Anahtar Kelimeler : Geri dönüşüm, mat sır, mermer atığı, atık yönetimi, seramik, sanat.
Article Received : 04.04.2018

Article Accepted: 09.10.2018

Research Article

\section{Manufacturing of Matte Glaze Compositions by Marble Waste Addition}

\begin{abstract}
With the widespread use of marble all over the world, beside marble mining, the amount of waste produced has also increased. In the study, by incorporation of marble waste to the standard matte glaze composition, new matte glazes were produced. The effect of using marble wastes on the properties of glaze body was investigated in terms of microstructural changes, phase formation, thermal behavior, color parameters and glossiness of glaze surfaces. To examine the effects on the color of the glazes, copper oxide (CuO) was added to the prepared glaze recipes. In matte glazes that were prepared without colorant addition, marble concentrations of more than 20 $\%$ resulted in slight lightening. With $\mathrm{CuO}$ addition into the composition, diverse colors and textures were obtained on the glaze surfaces. As the amount of waste in composition increases, the glaze surface becomes more textured and metallic. As a final output, Artistic ceramic forms were manufactured by using waste added glazes.
\end{abstract}

Keywords : Recycling, matte glaze, marble waste, waste management, ceramic, art.

\section{Giriş}

Atık maddelerin geri dönüştürülmesi azalan kaynakları korumakla birlikte doğaya atılmalarından kaynaklanan çevresel ve ekolojik zararların da önüne geçecektir. Atıkların hammadde olarak kullanılmasına yönelik yapılan başarılı AR-GE (araştırma ve geliştirme) çalışmaları çok karmaşık bir faaliyettir. $\mathrm{Bu}$ faaliyet malzeme bilimi, pazarlama gelişimi, performans değerlendirmesi ve çevre bilimleri gibi birçok farklı alandaki bilgileri de ihtiva eden multidisipliner bir yaklaşımı içermektedir (Menezes vd., 2012).

Potansiyelleri tespit edildikten sonra atık maddelerin yeniden kullanılması ve geri dönüşümü; ürünlerin çeşitlendirilmesine, üretim maliyetlerinin düşürülmesine, çeşitli endüstriyel sektörler için alternatif ham maddelerin sağlanmasına, yenilenebilir olmayan kaynakların korunmasına, enerjiden tasarruf edilmesine ve özellikle halk sağlığının geliştirilmesine katkıda bulunabilecek bir unsur olarak kabul edilmektedir (Menezes vd., 2012; Xu vd., 2012).

\footnotetext{
${ }^{*}$ Sorumlu Yazar Tel : 0.222.3350580 / 4237
} 
Mermer sedimentasyon ile oluşan kalsiyum karbonattır ve $\mathrm{H}_{2} \mathrm{SO}_{4}$ ile şiddetli tepkimeye girer (Sezer, 2013; El Haggar, 2010).

Dünya genelinde mermer atığının yaklaşık \% 40’ı taş ocaklarından çlkarılırken ve mermerin işlenmesi sırasinda meydana gelmektedir ve bu atıkların yakındaki boș çukurlara, yollara, nehir yataklarına, mera alanlarına, tarım arazilerine ya da katı atık depolama sahalarına atılması geniş çapta çevresel kirliliğe yol açmaktadır (Xu vd., 2012).

Dünyanın en zengin doğal taș olușumlarının bulunduğu Alp Bölgesi'nde konumlanmış olan Türkiye, çok çeşitli ve büyük miktarlarda mermer rezervlerine sahiptir. Bu önemli rezervler, Anadolu ile Trakya arasındaki geniş bir bölgeye dağılmıştır (Tosun ve Tatar, 2007; Celik ve Sabah, 2008).

Mermer atıklar oluştukları yere göre ocak ve işletme üretilen atıklar olarak sinıflandırılırlar. Boyutlarına göre ise şekillendirilmemiş bloklar, moloz (taş ocağında), ezilmiş plakalar ve talaş (ișleme tesislerinde) olarak adlandırılırlar. Tesislerde işlenen mermerlerin toz ve kum atıkları, işlenmiş mermerlerin yaklaşık \% 30'unu oluşturmaktadır (Buyuksagis vd, 2017).

Bu tür atıklar inert olarak sınıflandırılsalar da; çevreye dağıldıklarında aşırı ince taneli olmaları, toprağın geçirgenliği ve ayrıca yağmur suyu filtreleme süreçlerinden dolayı başkalaşım sonucunda ciddi zararlara neden olurlar (Limbachiya vd., 2004).

Mermer atığı esas olarak $\mathrm{CaCO}_{3}, \mathrm{CaO}, \mathrm{MgO}, \mathrm{SiO}_{2}, \mathrm{Al}_{2} \mathrm{O}_{3}$, $\mathrm{K}_{2} \mathrm{O}_{3}$ ve $\mathrm{Na}_{2} \mathrm{O}$ içermektedir. Çamur halindeki sulu mermer atığı açık alanlara boşaltıldı ̆̆ında tarım arazilerine ulaşarak toprak verimliliğini ve bitkilerin gelişimini azaltmaktadır. Sulu çamur kuruyunca, ince parçacıkları insan sağlığı üzerinde olumsuz etkiler yaratan hava kirliliğine sebep olur (Anwar vd., 2015; Erçikdi vd., 2015; Shah vd., 2015).

Farklı bir bakış açısıyla, üretim kaynakları ve tesislerinde üretilen büyük miktardaki atığa bağlı olarak, bu atığın katı atık depolama sahalarına nakliyesi için büyük miktarlarda paralar harcanmaktadır. Ekonomik açıdan, atıkların bu sahalarda birikmesi, birçok işletme için de baskı yaratan bir sorundur (Shirazi, 2011).

Mermer tozunun çeşitli endüstriyel kullanımları vardır, aslında yüksek orandaki ince taneli partiküller ve düşük yüzdeli metalik oksitler sayesinde, bu çok ince kireç parçacıkları, mikronize kalsiyum karbonatın kullanıldığı bir dizi endüstriyel uygulama için uygun bir şekilde toplanabilir ve piyasaya sürülebilir (Marras vd., 2010).

Literatürde mermer atıklarının çeşitli alanlarda kullanımıyla ilgili birçok çalışma bulunmaktadır. Literatür taraması, mermer çamuru atığının birçok uygulamaya entegre olabileceğini ve hammadde olarak kullanılabileceğini göstermektedir (Corinaldesi vd., 2010).

Sütçü ve ark. (2015), tuğla bileşimlerinde mermer atığının kullanımını araştırarak, atığın kil bazlı tuğlaların fiziksel, mekanik ve termal özelliklerine etkisini incelemişlerdir ] (Sutcu vd., 2015). Aliabdo ve ark. (2014) mermer atığının çimento ve beton üretiminde kullanımı ile ilgili bazı sonuçlar sunmuşlardır. Mermer tozunun bileşimde kumun yerine kullanılmasının, betonun mekanik özellikleri üzerinde çimento yerine kullanılmasından daha belirgin bir etkiye sahip olduğunu saptamışladır (Aliabdo vd., 2014). Hamaiedh (2010), Ürdün'deki dekoratif taș imalatı endüstrisinde mermer atıklarını içeren hammaddelerden üretilen seramik karoların fiziksel ve mekanik özelliklerindeki değişiklikleri incelemiştir (Al-Hamaiedh, 2010). Erdoğan ve ark. (2011) atık tozun çevresel etkilerinin en aza indirgenmesine ve inşaat sektöründe atık mermer tozunun değerlendirilmesiyle ekonomik faydaların en üst düzeye çıkarılmasına katkıda bulunmuşlardır (Erdoğan vd., 2011)

Montero ve ark. (2009) seramik karo bünye kompozisyonlarına ilave edilen mermer çamuru kalıntılarının mükemmel reaktiviteye sahip olduğunu, kil mineralleri ve kuvars ile kolayca reaksiyona girerek asıl partiküllerin daha iyi sinterlenmesini sağladığını göstermiştir (Montero vd., 2009).

Acchara (2006), Karaşahin (2007) ve Andreola (2016) endüstriyel atıkların seramik üretiminde yeniden kullanılabileceğini ve bu atıkların alternatif bir hammadde olarak doğal kaynaklara göre birçok avantaj sağlayabileceğini göstermek için geri dönüşüm üzerinde çalışmışlardır. Bütün bu çalıșmaların temel amacı mermer atıkların olumsuz çevresel etkilerini ortadan kaldırmak olmuştur (Acchar vd., 2006; Andreola vd., 2016).

Sırların üretimi, bileşimlerine farklı atık türlerinin dâhil edilebilir olması itibari ile geri dönüșüm malzemeleri için mükemmel bir alternatiftir. Bileşimdeki atık oranını değiştirerek mükemmel bir renk çeşitliliği ve doku elde edilebilir (Da Silva vd., 2012).

Stoneware sırları $1315{ }^{\circ} \mathrm{C}$ civarında ergimeye başlar, ayrıca sert ve dayanıklı yüzeylere sahiptirler. Bu sırlar geniş bir yüzey serbestisi ve renk olasılıkları sunmaktadır (Burleson, 2003). Sır yapma sanatı ve bilimi istenilen sonuca ulașmak için sır ham maddelerinin uygun seçimini, dağıtılmasını, karıştırılmasını, uygulanmasını ve pişirilmesini içerir (Rhodes, 2000).

Parlaklık veya yansımanın bulunmadığı donuk bir yüzeye sahip sırlar, mat sır olarak adlandırılır. Saten veya mat görünüm, sırın içinde dağılmış olan küçük kristallerin varlığına dayanan bir etkidir. Bu süreç tamamen ergimiș sırı soğurken ve kütlenin bir kısmı kristalleșirken meydana gelen devitrifikasyon olarak tanımlanır. Sır yüzeyine pürüzsüz ve kadifemsi bir 
görünüm verebilmek için kristaller çok küçük boyutta olmak ve sır yapısında dengeli bir şekilde dağılmak zorundadırlar. Yavaş soğuma, özellikle matlık sırdaki kristallerden kaynaklanıyorsa, doğal olarak sırda matlık oluşumunu destekler. Bu gibi mat sırlara onları iri hacimli görünür kristallere sahip sırlardan ayırt etmek için kripto kristalin sırlar denir (Eppler ve Eppler, 2000; Sheikhattar, 2016).

Kalsiyum içeren sırdaki matlık, anortit $\left(\mathrm{CaO} \cdot \mathrm{Al}_{2} \mathrm{O}_{3} \cdot 2 \mathrm{SiO}_{2}\right)$, vollastonit $\left(\mathrm{CaO} \cdot \mathrm{SiO}_{2}\right)$ ve gehlenit $\left(2 \mathrm{CaO} \cdot \mathrm{Al}_{2} \mathrm{O}_{3} \cdot \mathrm{SiO}_{2}\right)$ gibi kristallerin oluşumundan kaynaklanmaktadır (Sarjahani vd., 2010).

Mat yüzey elde etmek için sıra \% 20-30 oranında kalsiyum karbonat $\left(\mathrm{CaCO}_{3}\right)$ ilave edilir. Şeffaf sırlar ve diğer parlak sırlar başarıyla matlaștırılabilir. Toprak sırlarında kalsiyum oksit (CaO) $1100{ }^{\circ} \mathrm{C}$ 'nin altında sırı katılaștırma eğilimi gösterirken füzyonu da engeller, ayrıca soğuma sırasında anortit kristalleri oluşturmak için alüminyum oksit ve silis ile birleşir. Bir alkali oksit olmasına rağmen ergitici olarak davranmaz. 1100 ${ }^{\circ} \mathrm{C}$ 'nin üzerinde $\mathrm{CaO}$ bir ergitici olarak aktif hale gelir. $1100{ }^{\circ} \mathrm{C}^{\prime}$ nin üzerinde eriyen sırlarda, earthenware veya stoneware olsun ya da olmasın, $\mathrm{CaO}$ ilave edilmesi pişirme esnasında ergitici, soğuma sırasında kristal oluşturucu olarak görev yapar (Hamer ve Hamer, 2004). Aynı şekilde doğal hammaddeler gibi atıklar da üretim sırasındaki davranışlarının ve nihai ürünler üzerindeki etkilerinin doğru bir şekilde öngörülmesi için tanımlanabilir ve karakterize edilebilir (Tucci vd., 2004).

Yapılan çalışmada mat stoneware sır imalatında mermer atıklarının geri dönüşümü incelenmiștir. Atık ilavesinin; sırın rengi, dokusu, termal özellikleri ve mikroyapısı üzerindeki etkileri araştırılmıştır.

\section{Materyal ve Yöntem}

Şekil 1 mermer atıklarının temin edildiği Merdivenci Mermer San. ve Tic. A.Ş. mermer üretim tesisini göstermektedir. İşletmede blok mermerlerin sulu kesim yöntemi ile kesilmesi sırasında açığa çıkan ve çökeltme havuzlarında bekletilen ve herhangibir şekilde değerlendirilmeyip açık arazilerde depolanan atık mermer tozları temin edilmiştir. Çalışmada endüstriyel atık standart sır bileşimindeki mermer doğal ham maddesi ve kaolinin yerine ağırlıça \% 26'ya kadar kullanılmıştır. Sır hazırlama sürecinde ham madde olarak mermer atık, potasyum feldispat, kaolin, mermer, kuvars, çinko oksit ( $\mathrm{ZnO})$ ve bakır oksit (CuO) kullanılmıștır. Homojen sır reçeteleri elde etmek için mermer çamurları kurutulmuş ve 60 $\mu$ m'luk elekten geçirilmişilerdir.

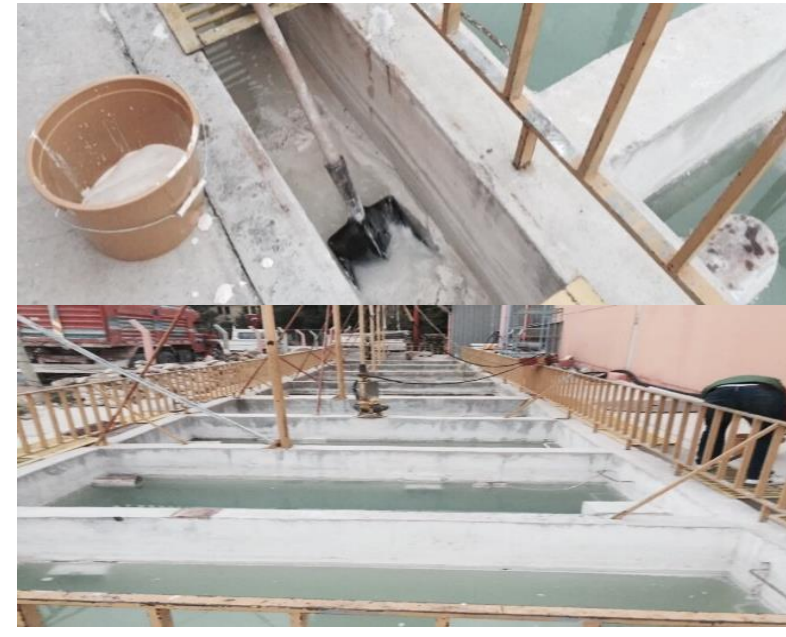

Şekil 1. Mermer işletmesine ait fotoğraf.

Kimyasal bileşimleri belirlemek amacı ile mermer atığının ve çalışmada kullanılan diğer ham maddelerin XRF (X-ışını floresan) analizleri yapılmıştır. Standart sir reçetesine (ST) \% 18, 22 ve 26 oranlarında mermer atığı ilave edilerek farklı sır bileşimleri hazırlandı. Standart sırdaki Seger formülü Tablo 1'de sunulmuştur (Nsiah, 2004).

Atık eklenen sır reçeteleri R1M, R2M ve R3M olarak kodlanmış ve Tablo 2'de sunulmuştur. Sır bileşimleri hazırlamak için, tartılmış hammaddeler 20 dakika boyunca bilyalı değirmenlerde yaş öğütülmüştür. Ögütme işleminden sonra, sır çamurları $60 \mu$ m'luk elekten geçirilerek stoneware bisküvilere uygulanmıştır. Sır çamurunun bir kısmı kurutularak ısı mikroskobu analizi için kullanılmıștır. Sırlanmış numuneler kurutma işleminin ardından 9 saat süreyle oksitleyici atmosferde $1160^{\circ} \mathrm{C}$ 'de pişirilmiștir. Pișmiș sırların morfolojik analizleri SEM (Taramalı Elektron Mikroskopu, Zeiss EVO $50 \quad 20 \quad$ kV'de) $\quad$ ile gerçekleştirilmiştir.

Tablo 1. Standart mat sıra ait Seger Formülü.

\begin{tabular}{|c|c|c|c|}
\hline Numune & \multicolumn{3}{|c|}{ Seger Formülü } \\
\hline ST & $\begin{array}{l}0,235 \mathrm{~K}_{2} \mathrm{O} \\
0,481 \mathrm{CaO} \\
0,284 \mathrm{ZnO}\end{array}$ & $0,433 \mathrm{Al}_{2} \mathrm{O}_{3}$ & $2,048 \mathrm{SiO}_{2}$ \\
\hline
\end{tabular}


Tablo 2. Hazırlanan sır reçetelerinin kimyasal bileşimleri (Ağırlıkça \%).

\begin{tabular}{|c|c|c|c|c|}
\hline Hammadde & ST & R1M & R2M & R3M \\
\hline $\begin{array}{c}\text { Potasyum } \\
\text { feldispat }\end{array}$ & 48,9 & 48,9 & 48,9 & 48,9 \\
\hline Kaolen & 19,2 & 19,2 & 15,2 & 11,2 \\
\hline Mermer & 18 & - & - & - \\
\hline Kuvars & 5,4 & 5,4 & 5,4 & 5,4 \\
\hline $\begin{array}{c}\text { ZnO (Çinko } \\
\text { Oksit) }\end{array}$ & 8,5 & 8,5 & 8,5 & 8,5 \\
\hline \begin{tabular}{c} 
Mermer Atığ \\
\hline
\end{tabular} & - & $\mathbf{1 8}$ & $\mathbf{2 2}$ & $\mathbf{2 6}$ \\
\hline
\end{tabular}

Nihai ürünlerin parlaklık ve renk parametreleri, Minolta marka 3600-d model spektrofotometre kullanılarak belirlenmiştir. Karakterizasyon testlerinin ardından üretimi yapılan atık ilaveli sır bileşimleri sanatsal uygulamalarda kullanılmıştır. Sır bileșimleri ağırlıkça \% 3 oranında $\mathrm{CuO}$ ile renklendirilerek akıtma yoluyla seramik formlara uygulanmıştır.

\section{Araştırma Bulguları}

Hammadde ve atıklara ait XRF sonuçları Tablo 3'te verilmiştir.

Tablo 3. Hammaddelerin kimyasal analiz sonuçları ( Ağırlıkça \%).

\begin{tabular}{|c|c|c|c|c|c|c|c|c|c|c|c|}
\hline Hammadde & $\mathrm{SiO}_{2}$ & $\mathrm{Al}_{2} \mathrm{O}_{3}$ & $\mathrm{Fe}_{2} \mathrm{O}_{3}$ & $\mathrm{CaO}$ & $\mathbf{M g O}$ & $\mathrm{Na}_{2} \mathrm{O}$ & $\mathbf{K}_{2} \mathrm{O}$ & $\mathrm{TiO}_{2}$ & $\mathbf{P}_{2} \mathrm{O}_{5}$ & $\mathbf{M n O}$ & $* \mathbf{A} . \mathrm{Z}$ \\
\hline K-Feldispat & 71,11 & 15,58 & 0,20 & 0,37 & 0,07 & 2,52 & 9,61 & 0,03 & 0,05 & - & 0,46 \\
\hline Mermer & 0,55 & - & 0,08 & 54,03 & 2,11 & 0,13 & - & - & - & - & 43,1 \\
\hline Kaolen & 70,28 & 13,92 & 1,80 & 2,51 & 1,83 & - & 2,64 & 0,80 & - & 0,09 & 6,13 \\
\hline Kuvars & 99,20 & - & 0,18 & 0,08 & - & 0,38 & 0,12 & - & - & - & 0,40 \\
\hline Mermer atığı & 0,52 & - & 0,10 & 53,51 & 1,66 & 0,09 & - & - & - & - & 44,12 \\
\hline
\end{tabular}

* Ateş Zaiyatı.

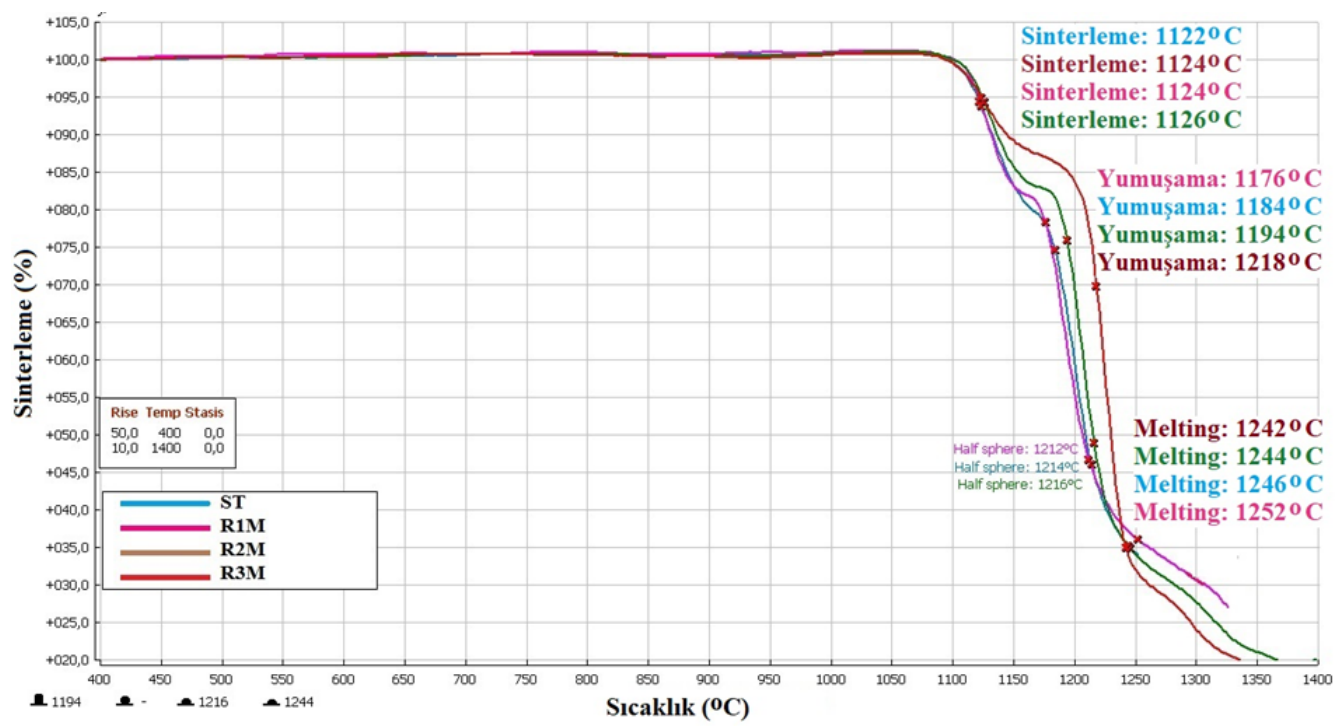

Şekil 2. Sır bünyelerine ait karşılaştırmalı ısı mikroskobu eğrileri.

Mermer atığının X-ışını analizlerine göre kalsit ana faz olarak gözlemlenmiştir (Yeşilay vd., 2017).

Üretilen mat sırların ısı mikroskobu analizi eğrileri Şekil 2'de görülmektedir. Sır bileşimine \% 22 ve 26 oranındaki atık ilavelerinde ergime sıcaklığının düştüğü görülmektedir.

Şekil 3 standart sır kompozisyonunun renk ve doku özelliklerinin atık ilavesiyle nasıl değiştiğini göstermektedir. Atık miktarının arttırılmasıyla mat sırın renginin açıldığı görülmektedir.

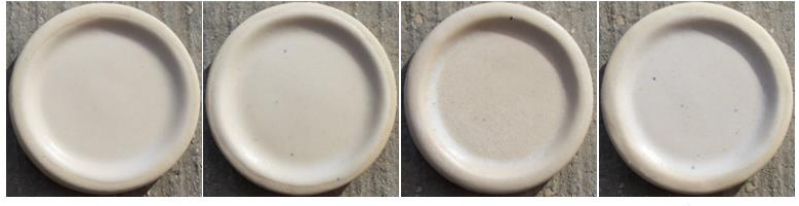

(a)

(b)

(c)

(d)

Şekil 3. Atık ilavesinin pişmiş sırın renk ve yüzey özelliklerine etkisi (a) ST (b) R1M (c) R2M (d) R3M. 
Tablo 4 her bir sırın kromatik koordinatlarını göstermektedir. Değerler 3 ölçümün ortalaması alınarak hesaplanmıștır. Üretilen sırın kromatik ölçüm sonuçları incelendiğinde atık ilavesinin artması sonucunda beyazlık ( $\mathrm{L}^{*}$ ) değerlerinin daha yüksek ve kırmızılık (a*) değerlerinin daha düşük çıktığı görülmektedir.

Tablo 4. Üretilen sırlara ait renk değerleri.

\begin{tabular}{|c|c|c|c|}
\hline $\begin{array}{c}\text { Numune } \\
\text { Adl }\end{array}$ & $\mathbf{L}^{*}$ & $\mathbf{a}^{*}$ & $\mathbf{b}^{*}$ \\
\hline ST & 82,68 & 2,78 & 12,14 \\
\hline R1M & 82,70 & 2,48 & 11,69 \\
\hline R2M & 82,70 & 2,43 & 12,5 \\
\hline R3M & 82,72 & 2,26 & 9,12 \\
\hline
\end{tabular}

* L*:Rengin parlaklığl (0: Siyah, 100: Beyaz), a*:Kırmızılık Yeşillik (-60: Yeşil, +60: Kırmızı, b*: Sarılık Mavilik (-60: Mavi,+60: Sarı).

Sırların parlaklık değerlerinin atık oranının \% 22'ye kadar yükselmesiyle birlikte arttığı gözlemlenmiştir. Bu orandan sonra parlaklık değerleri azalmıștır (Tablo 5). Sır bileşimlerinde içinde çok fazla miktarda kalsiyum oksit kullanıldığında, mat, dul lor pürüzlü yüzey üretecektir. $\mathrm{Bu}$, kalsiyumun sistemde gereken miktardan fazla miktarda mevcut olduğunda gösterdiği refrakter karakterinden ve eriyik içinde sınırlı miktarda çözünen kalsiyum silikatın yarattığı devitrifikasyondan kaynaklanır. Kalsiyum oksit çok yoğun olmayan mat olan sır yüzeylerinin üretilmesinde kullanılır. Bazı sırlarda kalsiyum miktarını arttırarak, sırın saydamlığını çok fazla etkilemeden mat bir yüzey elde edilebilir (Rhodes, 2000).

Tablo 5. $1160^{\circ} \mathrm{C}^{\prime}$ de pişirilen sırlara ait parlaklık değerleri.

\begin{tabular}{|c|c|c|}
\hline \multirow{2}{*}{ Numune Adı } & \multicolumn{2}{|c|}{ Parlaklık } \\
\cline { 2 - 3 } & $\mathbf{2 0} \circ$ & $\mathbf{6 0} \circ$ \\
\hline ST & 7,7 & $\mathbf{4 2 , 4}$ \\
\hline R1M & 26 & $\mathbf{5 2 , 1}$ \\
\hline R2M & 22,5 & $\mathbf{6 6 , 9}$ \\
\hline R3M & $\mathbf{2 , 7}$ & $\mathbf{1 2 , 1}$ \\
\hline
\end{tabular}

Sirlara \% 3 CuO ilavesinin yüzeyin renk ve dokusu üzerindeki etkisi Şekil 4'te görülmektedir.

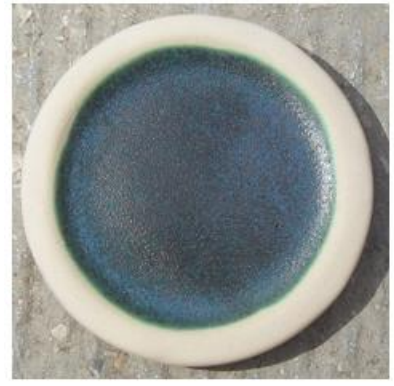

(a)

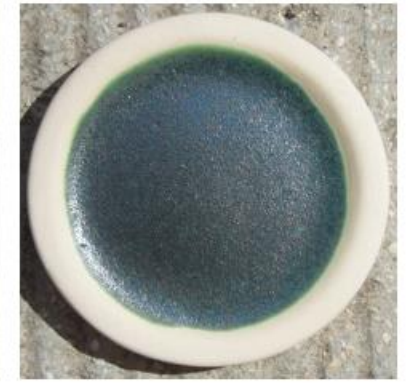

|(b)

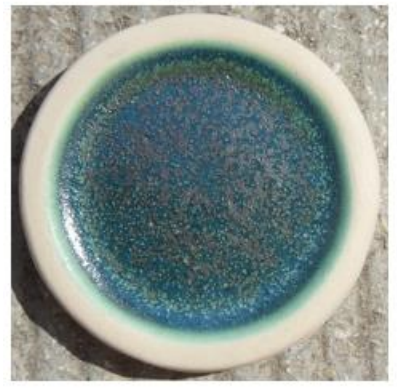

(c)

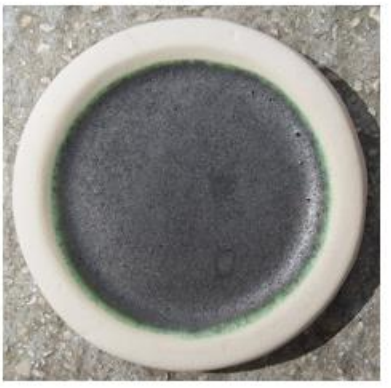

(d)
Şekil 4. CuO ilave edilmiş sırlara ait renk ve doku etkileri (a) ST (b) R1M (c) R2M (d) R3M.

Sır bileşimine bakır oksit ilavesi atık oranına bağlı olarak renk ve dokuda farklılaşmayla sonuçlanmıştır. Mermer yerine \%18 mermer atığının ilave edildiği \% 3 oranında $\mathrm{CuO}$ içeren sırın (R1M) renk ve yüzey dokusu standart sır ile oldukça benzerdir. Mermer ve kaolen yerine \% 20 atık ilave edildiğinde (R2M) oluşan renk mavimsi-yeșil tonlara dönüşmüștür; mermer atığı \% 26 (R3M) oranında kullanıldığında, klasik metalik sır dokusu meydana gelmiştir.

Normalde sır bileşimlerinde metalik etki \% 10'dan fazla $\mathrm{CuO}$ eklenerek elde edilebilir. R3M kodlu sırda bu etki \% 3 CuO ilavesi ile sağlanabilmiștir (Rhodes, 2000; Genç, 2013). Kristalin sırlarında kristal boyutunun ve şeklinin çeşitliliği ile eldesi mümkün olan renk yoğunluğu ve derinliği birçok seramikçinin ilgisini çekmiştir (Karasu vd., 2000). Sirlarda yüksek oranda kalsiyum kullanımı mat yüzeylerin elde edilmesine yardımcı olabilmektedir (Britt, 2007).

Şekil 5 ve 6'da sir yüzeylerinden alınan SEM görüntüleri ve EDX analizleri sunulmuştur. 


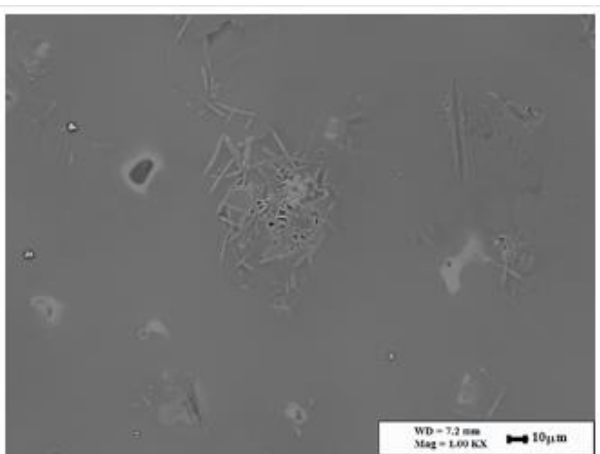

(a)

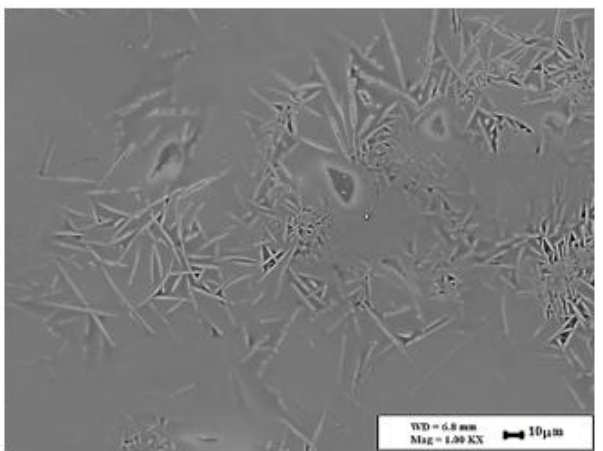

(c)

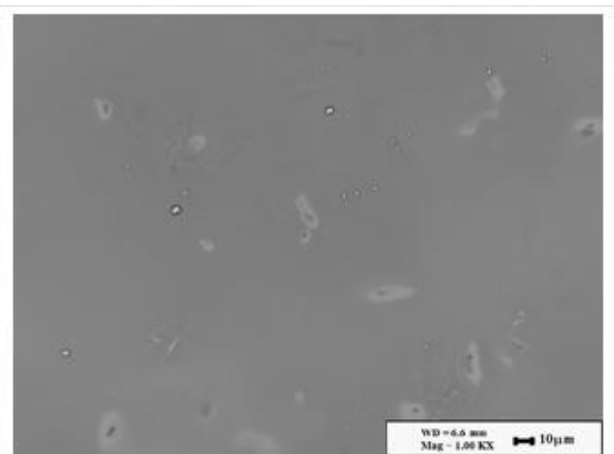

(b)

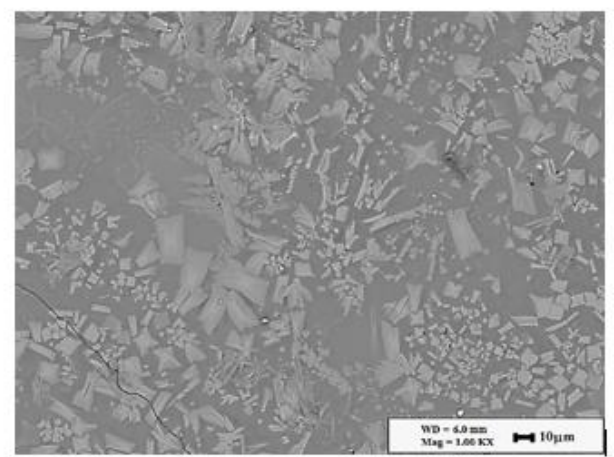

(d)

Şekil 5. Pişmiş sırlara ait SEM fotoğrafları (a) ST (b) R1M (c) R2M ve (d) R3M.

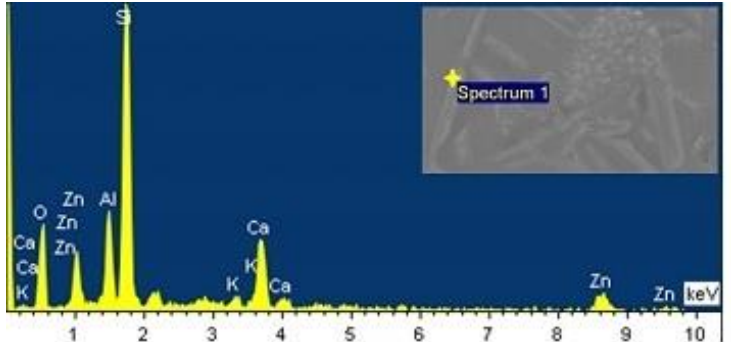

(a)

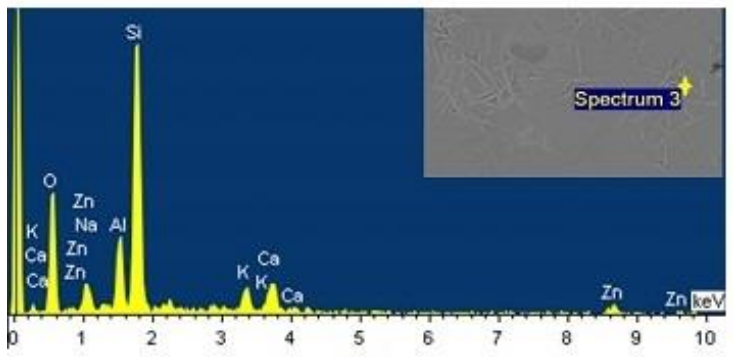

(c)

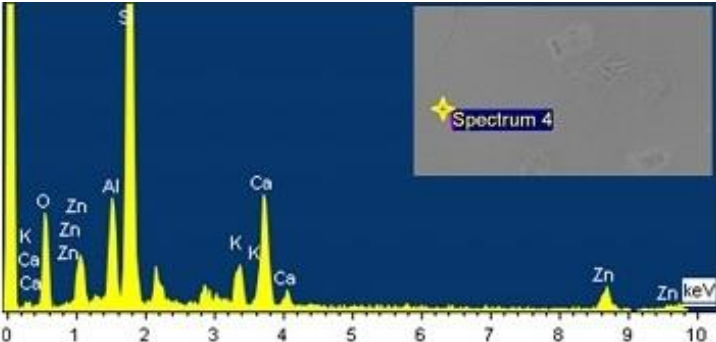

(b)

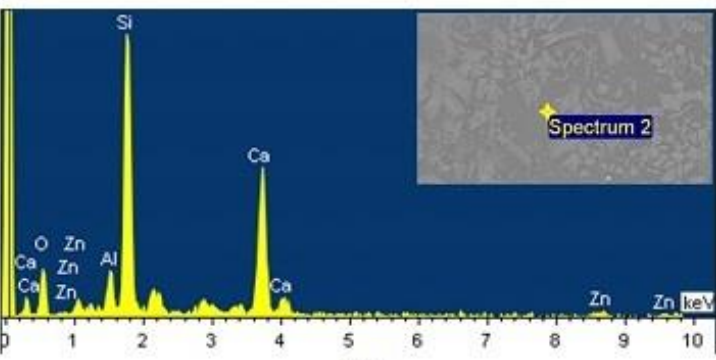

(d)

Şekil 6. Nihai ürünlere ait EDX analizleri (a) ST (b) R1M (c) R2M ve (d) R3M.

Şekil 5 (a) ve (d) 'de gösterilen SEM mikroyapıları incelendiğinde, sır bileșimindeki atık oranının artmasıyla anortit ve vollastonit gibi yüksek kalsiyumsilikat fazlarının oluşumunda belirgin bir artış meydana geldiği görülmektedir. Nihai sır bileşimindeki toplam kalsiyum miktarının artmasına yol açan bu fenomen, geri dönüşüm amaçlı kullanılan atık yüksek oranda kalsiyum içermesinden kaynaklanmıştır. Bu görüş Şekil 6 (a) ve (d) 'de gösterilen EDX sonuçlarını tam olarak karşılamaktadır. EDX analizinden anlaşıldığı üzere numunelerde atık miktarlarının artması ile Ca içeriğinde belirgin bir artışın olması ve aynı zamanda $\mathrm{Si}, \mathrm{Al}$ ve $\mathrm{O}$ 
içeriklerinin azalması sözkonusudur. Artan atık ilavesiyle birlikte Ca bakımından zengin dendrit-benzeri fazların gelişimi de SEM fotoğraflarında görülmektedir. Standart sırda kalisyumlu fazların oluşumu saptanamazken, Şekil 5 (b) ve (c) 'de faz oluşumu ve gelişimi açıkça görülmektedir. Atık oranı en yüsek olan R3M kodlu numunede, kalsiyum bakımından zengin major fazların oluşumu mikroyapı görüntülerinde saptanmışken bu durum Şekil 6 (d) 'de gösterilen kendi EDX sonuçlarıyla da uyumludur.

$1200{ }^{\circ} \mathrm{C}$ 'nin üstünde pişirilen sırlarda, pişirme esnasında volastonit $\left(\mathrm{CaO} . \mathrm{SiO}_{2}\right)$ kristalleri olușmaya başlar ve soğuma boyunca gelişmeye devam eder.

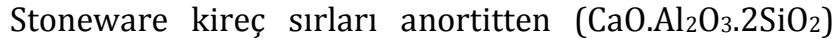
daha fazla volastonit kristalleri içermektedir (Hamer ve Hamer, 2004; Casasola vd., 2012).

Genel olarak yüksek orandaki CaO 'nun mikro-kristal gelişimini desteklediği bilinmektedir. Yeterince ergimiş sırlarda $\mathrm{CaO}, \mathrm{SrO}, \mathrm{BaO}$ gibi bazı oksit miktarları üst seviyede ya da limitlerin üstündeyse, soğuma sırasında yüzeyde bir mikro-kristal örgüsü oluşabilir ve ışığı dağıtarak mat bir görünüm sağlar (Sheikhattar, 2016). Mikroyapı görüntüleri incelendiğinde iğnemsi ve levha şeklindeki iki farklı kristalin özellikle R2M ve R3M kodlu sırlarda oluştuğu görülmektedir.

Şekil 7'de ST ve R2M kodlu sırların uygulanmasıyla üretilen sanat eserleri görülmektedir.

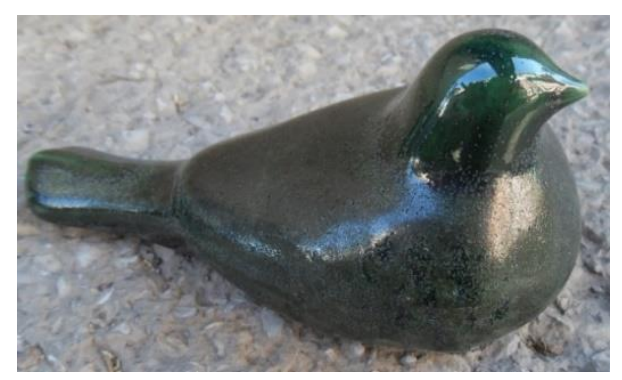

(a)

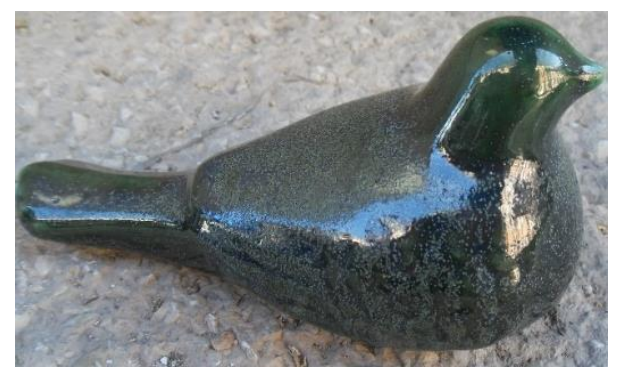

(b)

Şekil 7. Seramik formlar üzerine uygulanan sır örnekleri (a) ST (b) R2M.
Seramik formlarda R2M kodlu sir uygulamasinda $\mathrm{CaO}$ miktarının artmasıyla meydana gelen kristalleşme sonucunda matlık artmıştır. $\mathrm{CaO}^{\prime}$ in diğer toprak alkalilere göre en önemli farkı, ışık kırınımını arttırmadığı için parlaklık üzerinde fazla etkili olmamasıdır (Kartal, 1998).

\section{Sonuç ve Tartışma}

Standart sır reçetesindeki mermer ve kaolenin yerine aynı miktarlarda mermer atığı kullanılarak sır yüzeylerinde farklı renk ve yüzey dokuları elde edilmiştir. Sırdaki $\mathrm{CaO}$ oranı mermer atığıyla birlikte artmıştır ve bu değişiklik sırın beyazlık değerini bir miktar yükseltirken parlaklık değerini düşürmüştür. Mermer atığı ilavesi ergime davranışında önemli bir değişikliğe neden olmazken mikro yapıda oluşan kristalin fazların miktarını arttırmıştır. EDX analiziyle de saptanan kalsiyumca zengin major fazların olușumu atık ilavesinin en yüksek olduğu R3M sırının mikroyapısında gerçekleşmiştir. \% 22 atık ilave edilerek üretilen R2M sırında çatlaksız pürüzsüz bir sır yüzeyi elde edilmiştir.

Türkiye'nin Afyon bölgesinde üretilen mermer tozu ince partikül boyutuna sahip neredeyse saf bir kalsiyum karbonattır. Bu atık çeşitli endüstriyel veya sanatsal alanlarda kullanım alanı bulabilecek yüksek katma değerli bir ürün olarak görülebilir.

Çalışmada elde edilen sonuçlar mermer atığının mat sır bileşimlerinde hem renklendirici hem de ergitici bileșen olarak değerlendirilebileceğini göstermiştir. Dekoratif sırlar; çeşitli görsel efektler, renk tonları ve dokular elde etmek amacıyla sır bileşiminde mermer atığı kullanılarak üretilmiştir. Yapılan çalışma seramik üreticileri ve sanatçllar için ilginç görsel efektler ve daha ötesini keşfetmeyi sunmakla beraber çevre ve sağllğa zararlı atık maddenin etkisini azaltmaya katkıda bulunmayı da amaçlamıştır.

\section{Teşekkür}

$\mathrm{Bu}$ çalışmayı 1505E358 nolu proje kapsamında destekleyen Anadolu Üniversitesi Bilimsel Araştırma Projeleri Koordinasyon Birimi'ne teşekkür ederim.

\section{Kaynaklar}

Acchar, W., Vieira, F.A. and Hotza, D. (2006). Effect of marble and granite sludge in clay materials. Materials Science and Engineering: A, 419 (1-2), 306-309.

Al-Hamaiedh, H. (2010). Reuse of Marble Sludge Slime in Ceramic Industry. Jordan Journal of Civil Engineering; 4 (3), 264-271.

Aliabdo, A.A., Elmoaty, A.E.M., Auda E.M. (2014). Re-use 
of waste marble dust in the production of cement and concrete. Construction and Building Materials, 50, 2841.

Andreola, F., Barbieri, L., Lancellotti, I. (2016). Recycling of industrial wastes in ceramic manufacturing: state of art and glass case studies. Ceramics International, 42 (12), 13333-13338.

Anwar, A., Ahmad, S., Husain, S. (2015). Salvage of ceramic waste and marble dust for the refinement of sustainable concrete. International Journal of Civil Engineering and Technology (IJCIET), 6 (9), 79-92.

Britt, J. (2007). The Complete Guide to High-Fire Glazes: Glazing \& Firing at Cone 10, Sterling Publishing Company, Inc.

Burleson, M. (2003). The Ceramic Glaze Handbook: Materials, Techniques, Formulas, Lark Books; Revised edition.

Buyuksagis, I.S., Uygunoglu, T. and Tatar, E. (2017). Investigation on the usage of waste marble powder in cement-based adhesive mortar. Construction and Building Materials. 154 (15), 734-742.

Casasola, R., Rincón, J.M. and Romero, M. (2012). Glassceramic glazes for ceramic tiles-a review. Journal of Material Science. 47, 553-582.

Corinaldesi, V., Moriconi, G. and Naik, T.R. (2010). Characterization of marble powder for its use in mortar and concrete. Construction and Building Materials, 24,113-117.

Celik, M.Y. and Sabah, E. (2008). Geological and technical characterization of Iscehisar (Afyon-Turkey) marble deposits and the impact of marble waste on environmental pollution, Article in Journal of Environmental Management, 87 (1), 106-16.

Da Silva, R.C., Pianaro, S.A. and Tebcherani, S.M. (2012) Preparation and characterization of glazes from combinations of different industrial wastes. Ceramics International, 38 (4), 2725-2731.

El Haggar, S. (2010). Sustainable Industrial Design and Waste Management: Cradle-to-Cradle for Sustainable Development, Academic Press, 346.

Erçikdi, B., Külekçi, G. and Yilmaz, T. (2015). Utilization of granulated marble wastes and waste bricks as mineral admixture in cemented paste backfill of sulphide-rich tailings. Construction and Building Materials, 93, 573583.

Eppler, R.A. and Eppler, D.R. (2000). Glazes and Glass Coatings, Westerville, OH: American Ceramic Society.

Erdoğan, H.B., Yeprem, H.A., Günay, E. (2011). Evaluating waste marble dust as floor tile. Materials Testing, 53 (5), 290-294.

Genç, S. (2013). Artistic Ceramic Glazes (Artistik Seramik
Sirlar1) (In Turkish), Turkey, Boyut Press Inc.

Hamer, F. and Hamer, J. (2004). The Potter's Dictionary of Materials and Techniques, USA, University of Pennsylvania Press.

Limbachiya, M.C., Roberts, J.J. (2004). Construction Demolition Waste. Thomas Telford.

Karasu, B., Çakı, M. and Turan, S. (2000). The development and characterization of zinc crystal glazes used for amakusa-like soft porcelains. Journal of the European Ceramic Society, 20 (12), 2225-2231.

Kartal, A. (1998). Sır ve Sırlama Tekniği, Çizgi Matbaacılık, Ankara.

Marras, G., Careddu, N., Internicola, C. and Siotto, G. (2010). Recovery and reuse of marble powder byproduct, Conference: Global Stone Congress; Spain, 15 .

Menezes, R.R., Santana, L.N.L., Neves, G.A., Ferreira, H.C. (2012). Environmental Contamination, Chapter (11) Recycling of Mine Wastes as Ceramic Raw Materials: An Alternative to Avoid Environmental Contamination. 1st edition, InTech, ISBN: 978-953- 510120-8, DOI: $10.5772 / 31913$.

Montero, M.A., Jordan, M.M., Hernandez-Crespo, M.S. and Sanfeliu, T. (2009). The use of sewage sludge and marble residues in the manufacture of ceramic tile bodies. Applied Clay Science, 46 (4), 404-408.

Nsiah, J.K. (2004). Ceramics effect of different glaze-base systems on generation of colour. Quarterly Science Vision, 9 (1-2),1-10.

Rhodes, D. (2000). Clay and Glazes for the Potter, Krause Publications; 3 Rev Exp edition.

Romualdo Rodrigues, M., Lisiane Navarro L, Santana, Gelmires Araújo Neves and Heber Carlos Ferreira (2012). Recycling of Mine Wastes as Ceramic Raw Materials: An Alternative to Avoid Environmental Contamination, Environmental Contamination, Dr. Jatin Srivastava (Ed.), ISBN: 978-953-51-0120-8.

Sarjahani, R., Nemati, H.R., Atta M.S. (2010). Effect of pigments on crystal phases in non-fritted matte glaze. Ceramic Materials, 62 (4), 565-568.

Sezer, N. (2013). Production of Precipitated Calcum Carbonate from Marble Wastes, The Graduate School Of Natural And Applied Sciences of Middle East Technical Unıversity, The Degree Of Master Of Science In Mining Engineering, Ankara.

Shah, W., Nafees, M., Iqbal, M. (2015). Evaluation of marble slurry waste for preparation of commercial grade cement. J. Engg. and Appl. Sci., 34 (1), 28-37.

Sheikhattar, M., Attar, H., Sharafi, S., Carty, W. (2016). Influence of surface crystallinity on the surface roughness of different ceramic glazes. Materials 
Characterization, 118, 570-574.

Shirazi, E.K. (2011). Reusing of stone waste in various industrial activities. 2nd International Conference on Environmental Science and Development IPCBEE; Vol.4, IACSIT Press, Singapore, 217-219.

Sutcu, M., Alptekin, H., Erdogmus, E., Er, Y. and Gencel, O. (2015). Characteristics of fired clay bricks with waste marble powder addition as building materials. Construction and Building Materials, 82, 1-8.

Tosun, A. and Tatar, Ç. (2007). Investigation on the Possibilities to Increase Marble Export of Turkey, Dokuz Eylül University, Engineering Faculty, Journal of Science and Engineering, 9 (3),13-20.

Tucci, A., Esposito, L., Rastelli, E., Palmonari, C. and Rambaldi, E. (2004). Use of soda-lime scrap-glass as a fluxing agent in a porcelain stoneware tile mix. Journal of the European Ceramic Society, 24, 83-92.

Yeşilay, S., Çakı, M. and Ceylantekin, R. (2017). Recycling of Afyon-Iscehisar marble waste in transparent stoneware glaze recipes. J Aust Ceram Soc., 53, 475484.

Xu, J., Yasinzai, M., Lev, B. (2012). Proceedings of the Sixth International Conference on Management Science and Engineering Management: Focused on Electrical and Information Technology, Part IV: Industrial Engineering, Springer Science \& Business Media, 398, 2012. 